\title{
Are Oil Shocks Inflationary? Asymmetric and Nonlinear Specifications versus Changes in Regime*
}

\author{
Mark A. Hooker \\ Federal Reserve Board, Stop 71 \\ 20th \& C St., NW \\ Washington, DC 20551 \\ mhooker@frb.gov
}

December 1999

JEL Classification Codes E31, E24

Key words: Oil Shocks, Phillips Curves, Regime Shifts, Nonlinearity

\begin{abstract}
:
This paper estimates the effects of oil price changes on U.S. inflation in a Phillips curve framework, allowing for some of the asymmetries, nonlinearities, and structural breaks that have been found in the literature on the real effects of oil price shocks. It finds that since around 1980, oil price changes seem to affect inflation only through their direct share in a price index, with little or no pass-through into core measures, while before 1980 oil shocks contributed substantially to core inflation. This structural-break characterization appears robust to a variety of respecifications, and to fit the data better than asymmetric and nonlinear oil price alternatives. Preliminary evidence suggests that a change in the reaction of monetary policy to oil shocks is part of the explanation.
\end{abstract}

* The views expressed are those of the author and do not necessarily represent those of the Federal Reserve Board. I thank Bill English, Chris Hanes, Bill Nelson, and Robert Rich for helpful comments and suggestions. 


\section{Introduction}

The U.S. economy has achieved combinations of growth and inflation in recent years that many economists thought were no longer attainable. With the unemployment rate below most estimates of the NAIRU and falling for the past few years (Figure 1, top panel), many Phillips curve-based forecasts have predicted that inflation should be rising. However, as the middle panel shows, inflation has generally remained stable or even declined.

Many observers have attributed this anomalous behavior to special factors, like large declines in import prices associated with the Asian economic crisis. Important among those imports is crude oil, whose price fell from roughly \$23 per barrel in the fourth quarter of 1996 to just over $\$ 10$ at the end of 1998 . How much credit do falling oil prices deserve for the currently low levels of inflation? And will this year's record-setting spike (larger than the 1973, 1979, and 1990 shocks in nominal terms, as the bottom panel shows) lead to higher inflation? Since energy prices are a component of many Phillips curve models-the principal tool used by economists to explain inflation - answers to these questions could be read directly from model estimates. However, the Phillips curve literature has largely ignored a substantial and growing body of evidence that oil prices have asymmetric and nonlinear effects on real activity, as well as that structural instabilities exist in those relationships.1

In this paper, I evaluate the contributions of oil price changes to inflation in a Phillips-curve framework that allows for various nonlinearities and structural breaks. I find that, since around 1980, oil price changes seem to affect inflation mostly through their direct share in a price index, with little or no pass-through into core measures. By contrast, before 1980 oil shocks contributed substantially to core inflation. The econometric evidence for this result is highly significant and is robust to different economic activity, oil price, and inflation measures, changes in sample coverage, and lag specification. Furthermore, the structural break specification fits the data better than do several asymmetric and nonlinear oil price alternatives.

What could have caused such a change in economic structure? One component seems to be

1. Davis and Haltiwanger (1999) "view the evidence for asymmetric responses to oil price ups and downs as well established;" Lee Ni and Ratti (1995) and Hamilton $(1996,1999)$ have further argued that large or surprising oil price shocks have proportionally larger effects. Hooker (1999) finds that many of these results are sensitive to sample period and specification. The only paper I am aware of that modifies the oil price specification in a Phillips curve is Lown and Rich (1997), discussed below. 
that monetary policy in the Volcker-Greenspan era is significantly less accommodative of oil price shocks, and so they no longer trigger expectations of higher inflation. While not fully fleshed out, this story is supported by estimates of monetary policy reaction functions in Clarida, Galí and Gertler (1998) and Taylor (1998), and impulse-response functions from oil prices to the federal funds rate.

The rest of the paper is organized as follows. Section 2 estimates basic Phillips curves, with a focus on the oil price specification. Section 3 explores the structural stability of the oil price coefficients in these equations, and generates the key results of the paper. Section 4 evaluates the robustness of these results in several dimensions, including different inflation, economic activity, and oil price measures, lag structures, and sample periods. It also considers several asymmetric and nonlinear alternative specifications for oil prices. Section 5 looks briefly at some evidence on monetary policy as a cause, and Section 6 concludes.

\section{Oil prices in standard Phillips curves}

I begin by estimating two simple Phillips curves, based on Fuhrer (1995), for the CPI less food and energy, and for that same index with all items included. Fuhrer's estimates are with quarterly data, seasonally adjusted CPIs and unemployment rates, and include twelve lags of inflation, two lags of unemployment in the core and four in the all-items equation, and the contemporaneous change in the oil price. 2 I follow those specifications, with the small change of using the change in the PPI for crude oil relative to the respective price index as the oil price variable.

The equations may be written in slightly more general form as

$$
\pi_{t}=\alpha+\beta(\mathrm{L}) \pi_{t}+\gamma(\mathrm{L}) \mathrm{U}_{t}+\delta(\mathrm{L}) \mathrm{O}_{t}+\varepsilon_{t},
$$

where (L) signifies a polynomial in the lag operator. Fuhrer's sample began in 1960:II, because the core CPI is only available from 1957 on and thirteen quarters are lost to lags and differences. Here the dataset is extended through 1999:II, yielding 157 observations.

The first columns in each of Tables 1 and 2 summarize these regression results. While the coefficients on lagged inflation (not shown) and unemployment are similar across the two equations, and to Fuhrer's estimates, the oil price terms are quite different, with a sharper

2. All variables are converted to quarterly using averages of monthly data. 
contrast than Fuhrer found. In the core equation, the coefficient on oil prices is not anywhere near significant, with a $t$-statistic of only .56 , while in the all items equation, oil prices enter strongly with a $t$ of more than 4.0 .

The insignificant coefficient on oil prices in the core equation is at odds with the standard practice of including oil or other energy price variables in such equations. 3 However, it turns out that the lag structure for oil prices is important here. Oil's significance is greatly improved by replacing the contemporaneous change with its first and second lags, as shown in the second column of Table 1. By contrast, switching to lags of oil price changes in the all-items equation causes the fit to deteriorate markedly, as shown in the second column of Table 2. This makes sense: because energy prices are excluded from the core CPI, oil prices should affect it only with a lag. Energy has about a 7\% share in the all-items CPI, however, which is consistent with a substantial contemporaneous impact. The insignificance of lagged oil terms in this equation implies that most of the impact is felt within a quarter.

In the core inflation equation, the lagged oil price terms are strongly significant, with coefficients that sum to about 1.1. Given the units, this implies that a permanent doubling of oil prices would lead to a slightly more than 1 percentage point direct increase in inflation, whichsince lagged inflation has a coefficient of unity-is permanent. Indirect effects from oil prices to inflation, through the unemployment rate, would tend to moderate the direct effects.

\section{Issues in the specification of oil price terms}

The literature on the real effects of oil price shocks mentioned above suggests that the oil price-inflation relationship may not be well-captured by the linear, constant-coefficient specifications in most Phillips curves. In that literature, opinions on the best characterization include such diverse and refined positions as "oil prices by themselves do not have significant macroeconomic effects" (Bohi 1991), "oil price increases matter but decreases do not" (Mork 1989), "oil price increases matter if they are large enough relative to past experience" (Hamilton 1996), and "the effects oil price increases are a function of their size relative to their current degree of variability" (Lee, Ni and Ratti 1995).

3. Phillips curves or similar inflation equations with energy price terms include Fuhrer (1995), Gordon (1997), and Roberts (1997), among many others. Fuhrer used an oil price which was more significant contemporaneously than lagged. I use the more common crude oil PPI series, and consider several other oil prices in Section 4. 
There are several reasons why the relationships between oil prices and macroeconomic variables might be difficult to identify. One is the time series behavior of oil prices themselves. As the lower panel of Figure 1 shows, before 1981 oil prices rarely fell in nominal terms (due in large part to the regulatory price- and quantity-fixing schemes described in Hamilton 1985), and movements in oil prices tended to be concentrated into abrupt level increases. Prices then fell gradually from 1981 until 1985, collapsed in late 1985, and have swung widely in both directions through the present. It is only in the past 10 to 15 years, therefore, that data has existed to differentiate many hypotheses about specification. An extreme example is asymmetry: until we observe price decreases, nothing empirical can be said about the effects that they might have.

A second difficulty in identifying the effects of oil price shocks on macroeconomic variables is the lack of a dominant theoretical mechanism. Researchers have argued variously that oil primarily affects the macroeconomy as an import price, through the terms of trade; as an input price, through the production function either by increasing costs or by increasing uncertainty and thus deferring irreversible investment; as a shock to the aggregate price level which reduces real money balances, and as a relative price shock which leads to costly reallocation of resources across sectors. 4 Finally, the possibility that monetary policy systematically responds to oil price movements makes it difficult to identify which is the cause of any resulting macroeconomic effect. Indeed, Hoover and Perez (1994) model oil price shocks as a dummy variable for the spike periods, and they are nearly coincident with the Romer and Romer (1989) monetary contraction dummies.

There is also empirical evidence that oil price terms are not stable in samples that include recent data. For example, Mork (1989), Lee et. al. (1995), and Hooker (1996) show that Granger causality from oil prices (in log levels or changes) to output or unemployment deteriorates when data samples are extended past the mid-1980s. Several researchers, including Lee et. al. (1995) and Hamilton (1996), have argued that the greatly increased variability of oil prices after 1985 unmasked a misspecification, and that oil price changes must be run through complicated nonlinear and asymmetric filters in order to capture their macro-economic impacts since that time. However, Hooker (1997) has shown that these candidate respecifications still tend to exhibit structural instability in output and unemployment equations. 
Given this background, I begin the present investigation with tests for structural stability of the oil price coefficients in equation (1), and consider some nonlinear and asymmetric alternatives in Section 4.5 Such tests should allow for uncertainty about where a breakpoint may lie, due to the many potential candidates, including the different phases in the oil market and the change in Federal Reserve operating procedures from 1979 to 1982. Thus I use the Andrews (1993) test for a structural break at an unknown changepoint.

When this test is applied to the middle $70 \%$ of the sample (Andrews' recommended choice) for the core inflation equation, the maximal $\chi^{2}$ statistic is 59.1, which greatly exceeds the critical value for a $1 \%$ test, strongly supporting a structural break in the oil price coefficients. This value occurs with a breakpoint at 1980:II/III—interestingly, very close to the point where nominal oil prices began their first sustained decline. Figure 2 plots $F$-statistics for structural breaks in the equation as a whole, in the oil price coefficients, and in all but the oil price coefficients (which take one value before 1980:II and another after), across a range of breakpoints. It shows that the equation as a whole also indicates a break at 1980:II, with by far the greatest contribution coming from the oil price coefficients. 6

Column 3 of Table 1 then follows the suggestion from the Andrews test, adding interaction terms between the oil prices and a dummy variable that is one from 1980:III on (denoted D80). The results are striking. The fit is dramatically improved, with the adjusted $\mathrm{R}^{2}$ rising from .79 to .85 , and the equation's standard error falling by nearly $20 \%$, from 1.38 to 1.16 percentage points of inflation. The oil price coefficients are nearly five times as large as they were in column 2, with much larger $t$-statistics. Remarkably, the interaction terms are approximately equal and opposite to the oil price terms, and also very highly significant. In fact, the hypothesis that the oil price and interaction dummy coefficients sum to zero cannot be rejected, with a significance level of 0.48. The literal economic interpretation is that before 1980, oil price increases fed

4. Mork (1994) provides a useful summary of various channels by which oil price shocks might affect the economy. 5. Fuhrer tested the coefficients on lagged inflation and on unemployment for stability with Chow tests, and the overall equations for stability using dynamic simulations, and found them remarkably stable. He did not examine the oil price coefficients.

6. The portion of the sample examined for breaks in the oil price coefficients is 1966:I-1993:II; that range must be narrowed (as reflected in the figure) to test the much larger number of coefficients in the whole equation. The Andrews test 5\% critical values, in terms of $F$-statistics (which are shown because the $\chi^{2}$ values span a much wider range) are 5.90 for the oil price coefficient tests, and 2.24 and 2.16, respectively, for the all-coefficients and all-butoil tests. Thus some minor instability at 1980:II remains after taking account of that from the oil price coefficients. 
directly through to the core CPI, but since then the direct impact has been negligible.

The all-items CPI equation behaves very differently. Here, the maximal $\chi^{2}$ statistic in the Andrews test is only 4.89, well below the critical value even for a $10 \%$ test (of 7.17), indicating that the oil price coefficient is stable. When the D80 dummy variable is interacted with the oil price for comparison, as shown in column 3 of Table 2, the coefficient does increase from 0.79 to 1.66, but its significance is reduced and the interaction term is not statistically different from zero; it is also only about half the magnitude of the oil price coefficient. This regression provides only weak evidence that oil prices have had a reduced direct impact on overall CPI inflation since 1980.

\section{Robustness of the results}

The stark nature of the structural break apparent in the core inflation equation, and the fragile nature of oil price terms in much of the real effects literature, both call for a thorough assessment of robustness. The main dimensions I investigate are in the choice and specification of the economic activity, oil price, and inflation variables. I also test whether asymmetric and nonlinear responses to oil price shocks, popular hypotheses in the real effects literature, can explain the results found here. Of course, sensitivities to lag specification and subsample are checked at various stages of the investigation.

\section{A. Robustness to measure of resource pressure}

Three measures of economic activity are typically used in Phillips curves: unemployment rates, output gaps, and capacity utilization rates. While unemployment is the most common specification, one concern is that the NAIRU is time-varying, while specifications like (1) restrict

it to be constant. Some researchers deal with this by using a demographically adjusted unemployment rate, which eliminates demographically-driven changes in the NAIRU; others like Staiger, Stock and Watson (1997) or Gordon (1997) use more complicated equations that allow time-varying NAIRUs. The main difficulty with output gap measures is that they are heavily dependent upon assumptions regarding the behavior of potential output, an area of macroeconomics where there is little consensus.

I follow Gordon's (1989) advice: "if you want a variable that can be taken off the shelf from 
the government statisticians without any fine tuning, the Fed's capacity utilization rate captures the impact of the business cycle on the inflation process without the need for any adjustment or decomposition at all" (p. 213). The main drawback of this approach, and a reason for focusing on unemployment rate Phillips curves (in addition to their primacy in the literature and textbooks), is that the capacity utilization series does not begin until 1967.

Columns 4 through 6 of Tables 1 and 2 report estimates of the same equations, replacing unemployment with the (total) capacity utilization rate. Given two lags, the estimation sample begins in 1967:III. Despite the differences in measure of resource pressure and sample coverage, the estimates are very similar to those in columns 1-3. In the core inflation equations, the righthand side columns of Table 1, the oil price coefficients again exhibit a structural break in 1980, the estimated oil*D80 coefficients are equal and opposite to the oil price coefficients, the breakpoint, oil price coefficients, and interaction dummy coefficients are all highly statistically significant, and the equation's fit is substantially improved.

Similarly, the oil price coefficients do not exhibit a significant structural break in the allitems CPI equations, which are reported in the corresponding columns of Table 2. When a break is imposed in 1980, the estimates again provide some evidence that the contribution of oil price changes to inflation was moderated, but not eliminated, after 1980. These results give no indication that the results are sensitive to the measure of resource pressure or variation in estimation sample.

\section{B. Robustness to choice of oil or broader energy price}

The next dimension in which I test for robustness is the oil price, considering both a narrow and a broader substitute. As mentioned, the oil price used in Tables 1 and 2 is the growth rate of the PPI for crude oil relative to the respective inflation rate. 7 The narrow substitute is a series constructed by Mork (1989) to more accurately represent the marginal cost of oil as a production input, again relative to the respective inflation rate. Mork's series uses the PPI for crude oil through 1974 and the US Department of Energy's composite refiners' acquisition cost after 1974, with the 1971-74 observations adjusted for the effects of price controls (see Mork (1989) for details). I have simply extended this series to the end of the dataset. The results are so similar to

7. Hamilton used the PPI for crude oil in his in his original (1983) paper. 
those in Tables 1 and 2 that they are not reported (but are available upon request).

Many Phillips curve modelers use a broader energy price than just that for crude oil. Table 3 reports the equations of Tables 1 and 2 using the PPI for "fuels and related products and power," again relative to inflation (leaving off the capacity utilization versions to save space). In the core equation, shown in columns 1-3, the results indicate that entering this energy price with lags vs. contemporaneously produces a somewhat better fit, although the contemporaneous term is significantly different from zero. The results are quite similar in character to those with the narrower oil prices: the equation is unstable according to the Andrews test with the largest rejection again coming at 1980:II, and when D80 terms are interacted, they are highly significant, equal and opposite to the energy price terms, and greatly improve the fit of the equation (column 3).

The results with the all-items CPI, shown in columns 4-6, are also quite parallel to those with an oil price. The contemporaneous, but not the lagged, energy prices are significant (columns 4 vs. 5), there is no evidence for a structural break, and when the break interaction term is imposed, it is not significant, does not offset the oil price, and does not improve the fit of the equation (column 6). The energy price coefficients are also considerably larger than those on oil prices, which is consistent with fuel and power products' much larger direct weight in the indexes.

Taken together, the results do not appear sensitive to the choice of basic energy price. Subsection D below examines equations with nonlinear and asymmetric oil price terms.

\section{Other inflation measures}

The third dimension in which I explore robustness is the choice of price indexes. First, as a straight alternative for core inflation, I replace the CPI with the BEA's deflator for personal consumption expenditures less food and energy (chain-weighted). The estimates, reported in columns 1 and 2 of Table 4, are very similar to those with the core CPI. While the equations prefer one lag of unemployment rather than two, its coefficient is comparable to the sum of unemployment coefficients in the CPI equations. The coefficients on oil prices are smaller in the PCE equations, but again show strong evidence of a structural break in 1980, are much larger and more significant when the D80 dummy is interacted with the oil price terms, and statistically sum 
to zero with those interaction terms. Again, the fit of the equation is significantly improved with the imposition of the structural break in the oil price coefficients. Thus the core inflation results do not seem particular to the CPI index.

I next consider inflation as measured by the GDP deflator, which provides two interesting checks on the results obtained thus far. First, it is based on domestic production rather than consumption, and so has a much smaller energy share (the U.S. imports more than half its oil). In addition, this index is available from 1947, providing a much longer sample. Columns 3 through 6 of Table 4 report estimates of GDP deflator Phillips curves; again, only unemployment equations are reported.

Preliminary estimates indicate that one lag of unemployment is sufficient, and that contemporaneous and lagged oil prices result in approximately equal model fit. Column 3 of Table 4 reports the contemporaneous oil price equation estimates, and column 4 the one-lag estimates. In both equations, the unemployment rate is significantly different from zero, with a coefficient similar to the sum of those in the CPI equations, while neither oil price is significant. The Andrews test does not indicate a structural break in the oil price coefficient of either equation.

When the D80 dummy variable is nonetheless interacted with the oil price in each equation, in columns 5 and 6, the oil price coefficients are significantly different from zero and much larger. The interaction terms are also significant, and they are again statistically equal and opposite of the oil price coefficients, with $p$-values of .86 and .81 . The GDP deflator equation thus seems to exhibit some aspects of the all-items CPI equation-no structural break and no preference for lagged over contemporaneous oil prices - and some aspects of the core inflation equations, with larger oil price coefficients that are cancelled out after 1980. The results are consistent with the GDP deflator's lying part way between a core index and the total CPI in terms of energy share.

\section{Incorrect specification: asymmetric oil price effects?}

A potential alternative explanation for the core inflation results is asymmetric responses to oil price shocks, as advocated in real-side equations by Mork (1989), Hamilton (1996), and Davis and Haltiwanger (1999) among many others, and Lown and Rich (1997) in Phillips curves. Oil 
prices first started falling in nominal terms around 1980, so if oil price increases and decreases have asymmetric effects, that might show up as a structural break in a linear specification at about that time. In fact, Mork (1989) argued that allowing for asymmetry in the responses of output to oil shocks resolved an apparent structural break in 1986, when oil prices dropped sharply. If coefficients on positive and negative oil price changes are each structurally stable, that would support the argument that asymmetry, and not a change in the oil price-core inflation relationship, is at work.

Table 5 investigates this hypothesis, using Mork's oil price and unemployment. 8 Columns 1-3 relate to the core equations, and columns 4-6 to the all-items CPI equations. Columns 1 and 4 parallel the second columns of Tables 1 and 2, with oil prices at their preferred lag but without asymmetry or a structural break imposed (the only difference from Tables 1 and 2 is in the oil price). Columns 2 and 5 separate oil prices into increases and decreases: POIL is equal to the maximum of the oil price change and zero at each point, while NOIL is equal to the minimum of the oil price change and zero.

The estimates in column 2 suggest that oil price increases and decreases do have different effects on core inflation. The coefficients on oil price increases are significantly different from zero, and similar to the coefficients on oil prices themselves. The coefficients on oil price decreases, by contrast, are nowhere near statistical significance, and have a sum about one-half that of the increases coefficients. However, the improvement in the fit of the equation from allowing different coefficients on oil price increases and decreases, measured by its standard error or adjusted $R^{2}$, is barely perceptible at two decimal places. More importantly, those coefficients are not structurally stable. As indicated in the table, the maximal $\chi^{2}$ statistic exceeds the critical value for a $1 \%$ test (54.4 vs. critical value of 20.71), and the break test reaches its maximum value at precisely the same quarter as it does in the constrained specification, 1980:II. Column 3 then adds D80 interaction terms to each of the oil price variables. Here again, the fit is markedly improved, the oil price increase-interaction coefficients are highly significant, and they are equal and opposite to the oil price increase coefficients, with a $p$-value of .53 .

Columns 4-6 turn to the all-items CPI equation. Comparing columns 4 and 5, overall inflation also appears to respond asymmetrically to oil price changes. A test that the coefficients 
on oil price increases and decreases are equal is rejected at the $1 \%$ level, and here the Andrews test accepts stability. However, the asymmetry comes from price decrease coefficients that are larger than increase coefficients, rather than smaller or zero. When D80 terms are nevertheless interacted with the oil price increase and decrease terms, in the last column, their coefficients are only marginally significant and are not equal and opposite to the oil price coefficients.

Finally, specifications using the asymmetric and nonlinear oil price measures of Hamilton (1996) and Lee et. al. (1995) were explored.9 Neither produced a better fit than the linear and symmetric with structural break specifications; furthermore the coefficients on Hamilton's oil price (defined as the percentage increase from the previous year's high, if positive, and zero otherwise) also indicated structural breaks at 1980 and yielded the canceling-out result in the core inflation equation. Lee et. al.'s Garch-based oil price (positive oil price surprises scaled by conditional volatility) did not indicate a structural break nor canceling out, but produced a relatively poor fit.

Thus, the data seem to support a structural break and canceling out, rather than asymmetry or nonlinearity in the core inflation equation.

\section{A bit of evidence on changes in monetary policy as a cause}

Monetary policy ought to be a candidate explanation for any sustained change in the inflation process. Indeed, in the 1970s many economists argued that relative price changes, even those as large as the OPEC oil shocks, would only be inflationary if accommodated by monetary policy.

Some evidence does support the argument that monetary policy became significantly less accommodative of oil shocks around 1980, and thus helps explain the above results. For example, the large "Taylor rule" literature, which estimates equations for the federal funds rate as a function of deviations of output and inflation from their trend and target levels, typically finds that the coefficients on inflation (not specifically oil price) shocks imply considerably more aggressive responses after 1980 than before.10

8. The results are essentially unchanged using the PPI oil price or capacity utilization.

9. Lown and Rich (1997) used Hamilton's measure in a Phillips curve, and focused on wage-price specifications. 10. Clarida, Galí and Gertler (1998) found that "interest rate policy in the Volcker-Greenspan period appears to have been much more sensitive to changes in expected inflation than in the pre-Volcker period" (abstract). Taylor 
Some less-structural evidence on monetary policy reaction functions, obtained from VARs containing the federal funds rate and oil prices, also supports this view. Figure 3 reports impulse-response functions estimated on the subsamples 1954-80 and 1980-98, from quarterly VARs that include six lags of the unemployment rate, federal funds rate, GDP deflator inflation, import price inflation, and an oil price, in that order.11

As shown in the figure, the response of the funds rate to an oil price shock before 1980 was a significant easing of policy (after a fairly brief, mild, and borderline significant tightening). Panel 3a uses Mork's oil price (the PPI spliced with the refiner's acquisition cost), while panel $3 \mathrm{~b}$ uses Hamilton's net oil price increase series. This second oil price incorporates aspects of asymmetry and nonlinearity; however, the impulse-responses do not seem to be sensitive to the definition of the oil price. The bottom panels of the figure show funds rate changes in response to oil price shocks in the post-1980 period. The response is again an easing, but it is less than half the size in the earlier sample and only marginally significant. (Since oil price increases have a contractionary impact on inflation through their real effects, some monetary easing could be consistent with no net inflation effect). Again, the choice of oil price specification does not seem to matter much.

While the proposition that monetary policy has been less accommodative of price shocks in the 1980s and 1990s does not seem controversial, a well-known paper by Bernanke, Gertler and Watson ("BGW", 1997) found somewhat contradictory evidence. They estimated responses of the funds rate to oil price shocks (Hamilton's net oil price increase) in the subsamples 1966-75, 1976-85, and 1986-95 that correspond to a mild tightening, a more severe tightening, and a slight easing, respectively. I suggest several caveats to these results. First, those breakpoints do not correspond to any a priori events that might be expected to change the oil price-monetary policy relationship, but are simply thirds of the dataset; 1976-85 is particularly likely to combine different monetary regimes. Second, the statistical reliability of BGW's impulse-responses is quite limited: they reported one-standard error bands, or approximately $70 \%$ confidence intervals; many of their responses would not be significant with two-standard error bands. Also, their VARs include only six lags of monthly data; I have generally found oil price-

(1998) estimated a coefficient on inflation over 1987-97 about double its value from 1960-79.

11. Two-standard deviation bands, computed analytically as in Hamilton (1994, p. 336), are plotted along with the 
macroeconomy VARs with monthly data and short (less than a year) lags to be unstable. None of the many impulse-response functions that I have computed with quarterly VARs and longer lags indicates a tightening in data before 1980 .

One additional piece of evidence seems to conflict with the less-accommodative-Fed explanation: it would seem to imply that oil prices should have larger real effects along with smaller nominal effects. However, the real effects of oil prices literature generally finds smaller (as well as less robust) responses in the recent period. Perhaps, as Taylor (1998) finds, the response to output shocks has become even more aggressive than the response to price shocks, leading to smaller output and inflation deviations. The U.S. macro data certainly shows a dramatic reduction in variability in recent years, in nominal as well as real variables, which McConnell and Quiros (1997) date from 1984.

Overall, while this evidence is suggestive, an evaluation of the hypothesis that changed monetary policy is responsible for the dramatically reduced effects of oil prices on core inflation remains a topic for future research.

\section{Summary and Conclusions}

This paper estimates the effects of oil price changes on U.S. inflation in a Phillips curve framework, allowing for some of the asymmetries, nonlinearities, and structural breaks that have been found in the literature on the real effects of oil price shocks. It finds strong evidence of a structural break, with oil price changes making a substantial direct contribution to core inflation before 1980 but little or no pass-through since that time. Oil price effects on overall inflation are not significantly changed, and consistent with their direct shares in price indexes. The structural break specification provides a better fit to the data than do several asymmetric and nonlinear specifications stressed in the literature on the real effects of oil price shocks, and is robust to different specifications of the Phillips curve, measures of oil prices, and details of sample period, lag structure, etc.

Explanations for these results are more tentative. Evidence suggests that monetary policy has become less accommodative of oil price shocks, perhaps sufficiently so to prevent oil price changes from passing directly into core inflation. If this is indeed the mechanism, it is 
impressive that the Fed has managed to reduce output volatility at the same time. However, more work will be required to make a monetary policy explanation fully convincing. 


\section{References}

Andrews, Donald W.K. (1993), “Tests for Parameter Instability and Structural Change with Unknown Change Point", Econometrica 61, 821-856.

Bernanke, Ben S., Mark Gertler, and Mark Watson (1997), ““'Systematic Monetary Policy and the Effects of Oil Price Shocks," Brookings Papers on Economic Activity 1:1997, 91-157.

Bohi, Douglas R. (1991), "On the Macroeconomic Effects of Energy Price Shocks," Resources and Energy 13, 145-62.

Clarida, Richard, Jordi Galí, and Mark Gertler (1998), “Monetary Policy Rules and Macroeconomic Stability: Evidence and Some Theory," NBER Working Paper \#6442.

Fuhrer, Jeffrey C. (1995), "The Phillips Curve is Alive and Well”, New England Economic Review, March/April 1995, 41-56.

Gordon, Robert (1989), "Comments: The Phillips Curve Now and Then,” in Peter Diamond, ed., Growth/Productivity/Unemployment, MIT Press (Cambridge, Mass.)

Gordon, Robert (1997), “The Time-Varying NAIRU and its Implications for Economic Policy," Journal of Economic Perspectives 11, 11-32.

Hamilton, James D. (1983), "Oil and the Macroeconomy since World War II," Journal of Political Economy 91, 228-48.

Hamilton, James D. (1985), "Historical Causes of Postwar Oil Shocks and Recessions," Energy Journal 6, 97-116.

Hamilton, James D. (1994), Time Series Analysis, Princeton University Press (Princeton NJ).

Hamilton, James D. (1996), "Analysis of the Transmission of Oil Price Shocks Through the Macroeconomy," manuscript, U.C. San Diego Department of Economics.

Hooker, Mark A. (1996), "What Happened to the Oil Price-Macroeconomy Relationship?," Journal of Monetary Economics 38, 195-213.

Hooker, Mark A. (1997), "Exploring the Robustness of the Oil Price-Macroeconomy Relationship”, Federal Reserve Board (FEDS) Working Paper 1997-56.

Hooker, Mark A. (1999), "Oil and the Macroeconomy Revisited”, Federal Reserve Board (FEDS) Working Paper 1999-43.

Hoover, Kevin D. and Stephen J. Perez (1994), “Post Hoc Ergo Propter Hoc Once More: 
An Evaluation of 'Does Monetary Policy Matter?' in the Spirit of James Tobin,' Journal of Monetary Economics 34, 47-73.

Lee, Kiseok, Shawn Ni, and Ronald Ratti (1995), "Oil Shocks and the Macroeconomy: The Role of Price Variability," Energy Journal 18, 39-56.

Lown, Cara S. and Robert W. Rich (1997), "Is there an Inflation Puzzle?", FRBNY Economic Policy Review December 1997, 51-69.

McConnell, Margaret M. and Gabriel Perez Quiros (1997), "Output Fluctuations in the United States: What Has Changed Since the Early 1980s?”, Federal Reserve Bank of New York Working Paper 9735.

Mork, Knut Anton (1989), "Oil and the Macroeconomy when Prices Go Up and Down: An Extension of Hamilton's Results," Journal of Political Economy 97, 740-4.

Mork, Knut Anton (1994), "Business Cycles and the Oil Market," Energy Journal 15 (Special Issue), 15-38.

Roberts, John M. (1997), “Is Inflation Sticky?”, Journal of Monetary Economics 39, 173-96.

Romer, C.D. and D.H. Romer (1989), "Does Monetary Policy Matter? A New Test in the Spirit of Friedman and Schwartz," NBER Macroeconomics Annual 4, 121-70.

Staiger, Douglas, James H. Stock, and Mark W. Watson (1997), "The NAIRU, Unemployment, and Monetary Policy,” Journal of Economic Perspectives 11, 33-49.

Taylor, John B. (1998), “An Historical Analysis of Monetary Policy Rules,” NBER Working Paper \#6768. 


\section{Table 1: Phillips curve regressions, Core CPI with PPI oil price}
(1)
(2)
(3)
(4)
(5)
(6)

$\begin{array}{cccc}\mathrm{U}_{\mathrm{t}-1} & -1.91 & -1.98 & -2.06 \\ & (-4.52) & (-4.89) & (-6.05) \\ & & & \\ \mathrm{U}_{\mathrm{t}-2} & 1.68 & 1.74 & 1.74 \\ & (3.94) & (4.25) & (5.04)\end{array}$

CAPU $_{t-1}$

$\begin{array}{ccc}.47 & .49 & .54 \\ (3.66) & (3.96) & (5.31) \\ & & \\ -.29 & -.32 & -.35 \\ (-2.12) & (-2.44) & (-3.21)\end{array}$

$\mathrm{Oil}_{\mathrm{t}}$

.11

.07

$(.56)$

(.36)

$\mathrm{Oil}_{\mathrm{t}-1}$

.56

2.44

.48

2.44

(2.38) (5.79)

$(1.92)$

(5.56)

$\mathrm{Oil}_{\mathrm{t}-2}$

.58

2.70

.55

2.63

(2.42)

(5.85)

(2.16)

(5.53)

$\mathrm{D} 80 * \mathrm{Oil}_{\mathrm{t}-1}$

$-2.32$

$-2.42$

$(-4.96)$

(-4.99)

$\mathrm{D} 80 * \mathrm{Oil}_{\mathrm{t}-2}$

$-2.49$

$-2.43$

$(-5.00)$

$(-4.72)$

$\mathrm{R}^{2}$

.77

.79

.85

.73

.75

.83

ser

1.44

1.38

1.16

1.51

1.45

1.19

DW

1.92

1.90

1.92

1.88

1.85

1.87

$p$-value

$<.01$

.48

$<.01$

.66

Notes: Sample is 1960:II-99:II for the unemployment equations, columns 1-3, and 1967:II-99:II for the capacity utilization equations, columns 4-6. All regressions include a constant term and 12 lags of inflation in addition to variables reported. $t$-statistics are in parentheses. Oil is the growth rate of the PPI for crude oil relative to the core CPI. $\mathrm{R}^{2}$ is adjusted, ser is the standard error of the regression, and $\mathrm{DW}$ is the Durbin-Watson statistic. $p$-values in columns 2 and 5 are for the Andrews (1993) stability test on oil price coefficients, and in columns 3 and 6 for the hypothesis that the oil price and interaction terms sum to zero. 


\section{Table 2: Phillips curve regressions, All-items CPI with PPI oil price}
(1)
(2)
(3)
(4)
(5)
(6)

\begin{tabular}{|c|c|c|c|}
\hline $\mathrm{U}_{\mathrm{t}-1}$ & $\begin{array}{c}-2.19 \\
(-5.32)\end{array}$ & $\begin{array}{c}-2.31 \\
(-5.30)\end{array}$ & $\begin{array}{c}-2.21 \\
(-5.41)\end{array}$ \\
\hline $\mathrm{U}_{\mathrm{t}-2}$ & $\begin{array}{c}1.96 \\
(4.83)\end{array}$ & $\begin{array}{c}2.05 \\
(4.80)\end{array}$ & $\begin{array}{c}1.96 \\
(4.88)\end{array}$ \\
\hline
\end{tabular}

CAPU $_{\mathrm{t}-1}$

$\begin{array}{ccc}.58 & .60 & .58 \\ (5.09) & (4.99) & (5.19) \\ & & \\ -.37 & -.41 & -.38 \\ (-3.07) & (-3.18) & (-3.17)\end{array}$

$\mathrm{Oil}_{\mathrm{t}}$

.79

1.66

.76

1.57

(4.16)

(3.09)

(3.99)

$\mathrm{Oil}_{\mathrm{t}-1}$

.33

.28

(1.21)

(1.01)

$\mathrm{Oil}_{\mathrm{t}-2}$

$-.41$

$-.27$

$(-1.53)$

(-.98)

D80*Oil ${ }_{\mathrm{t}}$

$-.99$

$-.91$

(-1.73)

$(-1.58)$

$\mathrm{R}^{2}$

.82

.80

.82

.82

.79

.82

ser

1.40

1.48

1.39

1.41

1.50

1.40

DW

1.92

1.95

1.99

1.96

1.94

2.04

$p$-value

$>.10$

$<.01$

$>.10$

$<.01$

Notes: Sample is 1960:II-99:II for the unemployment equations, columns 1-3, and 1967:II-99:II for the capacity utilization equations, columns 4-6. All regressions include a constant term and 12 lags of inflation in addition to variables reported. $t$-statistics are in parentheses. Oil is the growth rate of the PPI for crude oil relative to the allitems CPI. $\mathrm{R}^{2}$ is adjusted, ser is the standard error of the regression, and DW is the Durbin-Watson statistic. $p$ values in columns 2 and 5 are for the Andrews (1993) stability test on oil price coefficients, and in columns 3 and 6 for the hypothesis that the oil price and interaction terms sum to zero. 


\section{Table 3: Phillips curve regressions, CPI with broader energy price}

\section{Core CPI Inflation}

(1)

(2)

(3)

$\mathrm{U}_{\mathrm{t}-1}$

$-1.85$

$-2.05$

$(-5.31)$

$-2.12$

$(-4.53)$

$(-6.27)$

$\mathrm{U}_{\mathrm{t}-2}$

$\begin{array}{ccc}1.66 & 1.83 & 1.84 \\ (4.03) & (4.67) & (5.39)\end{array}$

$\mathrm{EGY}_{\mathrm{t}}$

1.85

(3.23)

$\mathrm{EGY}_{\mathrm{t}-1}$

2.35

4.39

(4.59)

$\mathrm{EGY}_{\mathrm{t}-2}$

1.49

(2.32)

3.24

(2.93)

$\mathrm{D} 80 * \mathrm{EGY}_{\mathrm{t}}$

D80*EGY $\mathrm{t}_{\mathrm{t}-1}$

D80*EGY ${ }_{\mathrm{t}-2}$

$(-3.52)$

$-3.19$

$(-2.60)$

$\mathrm{R}^{2}$

.78

.81

1.39

1.32

1.94

2.05

$<.01$

$p$-value

.84
3.98

(6.94)

$\begin{array}{ll}-2.21 & -2.30\end{array}$

$(-5.88) \quad(-5.27)$

1.98

(5.36)

2.03

(4.76)

1.98
$(5.40)$

$(-5.94)$

(6)

$-2.22$

5.14

(5.79)

1.00

(1.27)

$-1.09$

$(-1.39)$

$-1.81$

$(-1.70)$

$\begin{array}{lllllll}\text { DW } & 2.05 & 1.94 & 1.76 & 1.90 & 1.95 & 1.90\end{array}$

$>.10<.01$

Notes: Sample is 1960:II-99:II. EGY is the growth rate of the PPI for fuels and related products and power, BLS series WPU05, relative to the inflation measure used. All regressions include a constant term and 12 lags of inflation in addition to variables reported. $t$-statistics are in parentheses. $\mathrm{R}^{2}$ is adjusted, ser is the standard error of the regression, and DW is the Durbin-Watson statistic. $p$-values in columns 2 and 5 are for the Andrews (1993) stability test on energy price coefficients, and in columns 3 and 6 for the hypothesis that the energy price and interaction terms sum to zero. 


\section{Table 4: Phillips curve regressions, Other Price Indexes}

\begin{tabular}{|c|c|c|c|c|c|c|}
\hline & \multicolumn{2}{|c|}{ Core PCE } & \multicolumn{4}{|c|}{ GDP Deflator } \\
\hline & (1) & (2) & (3) & (4) & (5) & (6) \\
\hline $\mathrm{U}_{\mathrm{t}-1}$ & $\begin{array}{c}-.25 \\
(-3.22)\end{array}$ & $\begin{array}{c}-.28 \\
(-3.21)\end{array}$ & $\begin{array}{c}-.22 \\
(-2.27)\end{array}$ & $\begin{array}{c}-.22 \\
(-2.29)\end{array}$ & $\begin{array}{c}-.20 \\
(-2.13)\end{array}$ & $\begin{array}{c}-.20 \\
(-2.11)\end{array}$ \\
\hline $\mathrm{Oil}_{\mathrm{t}}$ & & & $\begin{array}{l}.13 \\
(.64)\end{array}$ & & $\begin{array}{c}.69 \\
(1.32)\end{array}$ & \\
\hline $\mathrm{Oil}_{t-1}$ & $\begin{array}{c}.30 \\
(2.06)\end{array}$ & $\begin{array}{l}1.68 \\
(5.96)\end{array}$ & & $\begin{array}{l}.22 \\
(.90)\end{array}$ & & $\begin{array}{c}1.30 \\
(2.51)\end{array}$ \\
\hline $\mathrm{Oil}_{\mathrm{t}-2}$ & $\begin{array}{c}.18 \\
(1.24)\end{array}$ & $\begin{array}{c}1.15 \\
(3.61)\end{array}$ & & & & \\
\hline $\mathrm{D} 80 * \mathrm{Oil}_{\mathrm{t}}$ & & & & & $\begin{array}{c}-.66 \\
(-1.17)\end{array}$ & \\
\hline $\mathrm{D} 80 * \mathrm{Oil}_{\mathrm{t}-1}$ & & $\begin{array}{c}-1.72 \\
(-5.41)\end{array}$ & & & & $\begin{array}{c}-1.37 \\
(-2.36)\end{array}$ \\
\hline $\mathrm{D} 80 * \mathrm{Oil}_{\mathrm{t}-2}$ & & $\begin{array}{l}-1.10 \\
(-3.15)\end{array}$ & & & & \\
\hline $\mathrm{R}^{2}$ & .86 & .90 & .69 & .69 & .69 & .70 \\
\hline ser & .86 & .75 & 1.51 & 1.50 & 1.50 & 1.48 \\
\hline DW & 1.99 & 2.00 & 1.98 & 1.99 & 2.01 & 2.06 \\
\hline$p$-value & $<.01$ & .92 & $>.10$ & $>.10$ & .86 & .81 \\
\hline
\end{tabular}

Notes: Sample is 1950:II-99:II for the GDP deflator regressions and 1962:II-99:II for the core PCE equations. All regressions include a constant term and 12 lags of inflation in addition to variables reported. Oil is the growth of the PPI for crude oil relative to the inflation measure used. $t$-statistics are in parentheses. $\mathrm{R}^{2}$ is adjusted, ser is the standard error of the regression, and DW is the Durbin-Watson statistic. $p$-values in columns 1,3 and 4 are for the Andrews (1993) stability test on oil price coefficients, and in columns 2, 5 and 6 for the hypothesis that the oil price and interaction terms sum to zero. 


\section{Table 5: Phillips curve regressions, Oil Price Asymmetry vs. Structural Breaks}

\begin{tabular}{cc} 
Core CPI \\
\hline (1) (2)
\end{tabular}

\begin{tabular}{ccc}
\multicolumn{3}{c}{ All-items CPI } \\
\hline$(4)$ & $(5)$ & $(6)$ \\
-2.19 & -2.16 & -2.20 \\
$(-5.32)$ & $(-5.36)$ & $(-5.50)$ \\
1.96 & 1.94 & 1.95 \\
$(4.83)$ & $(4.90)$ & $(4.97)$
\end{tabular}

$\begin{array}{lc}\mathrm{U}_{\mathrm{t}-1} & -1.98 \\ & (-4.96) \\ \mathrm{U}_{\mathrm{t}-2} & 1.75 \\ & (4.32) \\ \text { Oil }_{\mathrm{t}} & \\ & \\ \text { Oil }_{\mathrm{t}-1} & .51 \\ \text { Oil }_{\mathrm{t}-2} & (2.38) \\ & .68 \\ & (3.08)\end{array}$

POil $_{t}$

$\begin{array}{cc}-2.01 & -1.99 \\ (-4.98) & (-5.76) \\ 1.78 & 1.71 \\ (4.36) & (4.89)\end{array}$

.79

(4.16)

(3.08)

\begin{tabular}{|c|c|c|c|c|c|c|}
\hline & & & & & $(2.76)$ & $(2.82)$ \\
\hline POil $_{t-1}$ & & $\begin{array}{c}.66 \\
(2.47)\end{array}$ & $\begin{array}{c}1.81 \\
(4.86)\end{array}$ & & & \\
\hline $\mathrm{POil}_{\mathrm{t}-2}$ & & $\begin{array}{c}.61 \\
(2.26)\end{array}$ & $\begin{array}{c}2.44 \\
(6.07)\end{array}$ & & & \\
\hline $\mathrm{NOil}_{\mathrm{t}}$ & & & & & $\begin{array}{c}2.59 \\
(3.80)\end{array}$ & $\begin{array}{c}6.98 \\
(1.45)\end{array}$ \\
\hline $\mathrm{NOil}_{\mathrm{t}-1}$ & & $\begin{array}{c}-.14 \\
(-.20)\end{array}$ & $\begin{array}{r}-1.65 \\
(.54)\end{array}$ & & & \\
\hline NOil $_{t-2}$ & & $\begin{array}{c}.88 \\
(1.26)\end{array}$ & $\begin{array}{c}-.89 \\
(-.30)\end{array}$ & & & \\
\hline $\mathrm{D} 80 * \mathrm{POil}_{\mathrm{t}}$ & & & & & & $\begin{array}{c}-1.13 \\
(-2.00)\end{array}$ \\
\hline D80*POil ${ }_{\mathrm{t}-1}$ & & & $\begin{array}{c}-1.57 \\
(-3.45)\end{array}$ & & & \\
\hline D80*POil ${ }_{\mathrm{t}-2}$ & & & $\begin{array}{c}-2.34 \\
(-4.97)\end{array}$ & & & \\
\hline $\mathrm{D} 80 * \mathrm{NOil}_{\mathrm{t}}$ & & & & & & $\begin{array}{l}-4.31 \\
(-.92)\end{array}$ \\
\hline D80*NOil ${ }_{\mathrm{t}-1}$ & & & $\begin{array}{l}1.20 \\
(.40)\end{array}$ & & & \\
\hline $\mathrm{D} 80^{*} \mathrm{NOil}_{\mathrm{t}-2}$ & & & $\begin{array}{l}1.43 \\
(.48)\end{array}$ & & & \\
\hline $\mathrm{R}^{2}$ & .79 & .79 & .85 & .82 & .83 & .83 \\
\hline ser & 1.36 & 1.37 & 1.17 & 1.40 & 1.37 & 1.36 \\
\hline DW & 1.93 & 1.92 & 1.96 & 1.92 & 1.94 & 2.04 \\
\hline$p$-value & & $<.01$ & .53 & & $>.10$ & $<.01$ \\
\hline
\end{tabular}

Notes: See notes to Table 1. $p$-values in columns 2 and 5 are for the Andrews (1993) stability test on oil price coefficients, and in columns 3 and 6 for the hypothesis that the respective oil price and interaction terms sum to zero. 
Figure 1: Unemployment, Inflation and Oil Prices, 1957:II-1999:II
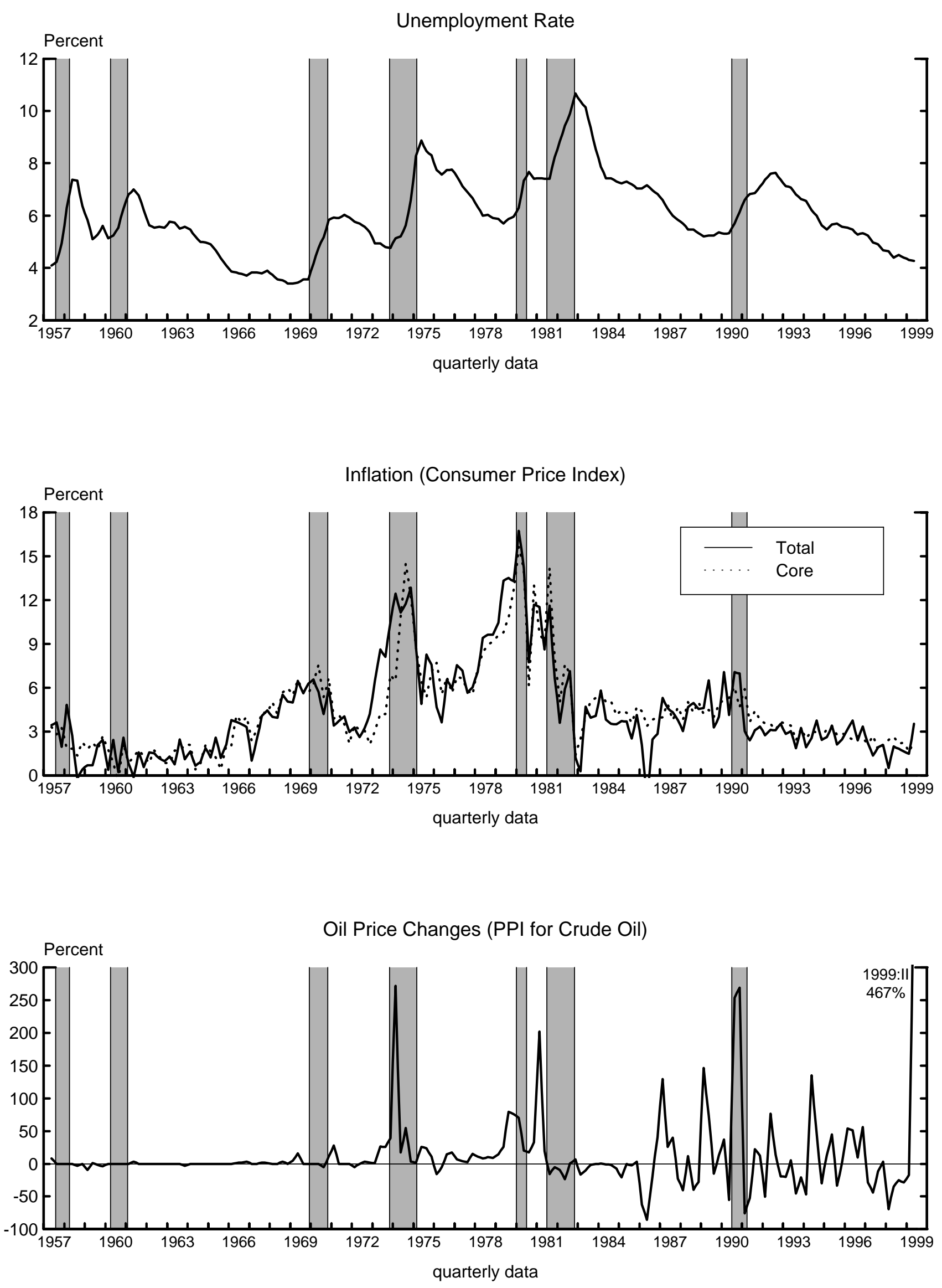
Figure 2: F-Statistics for Structural Breaks

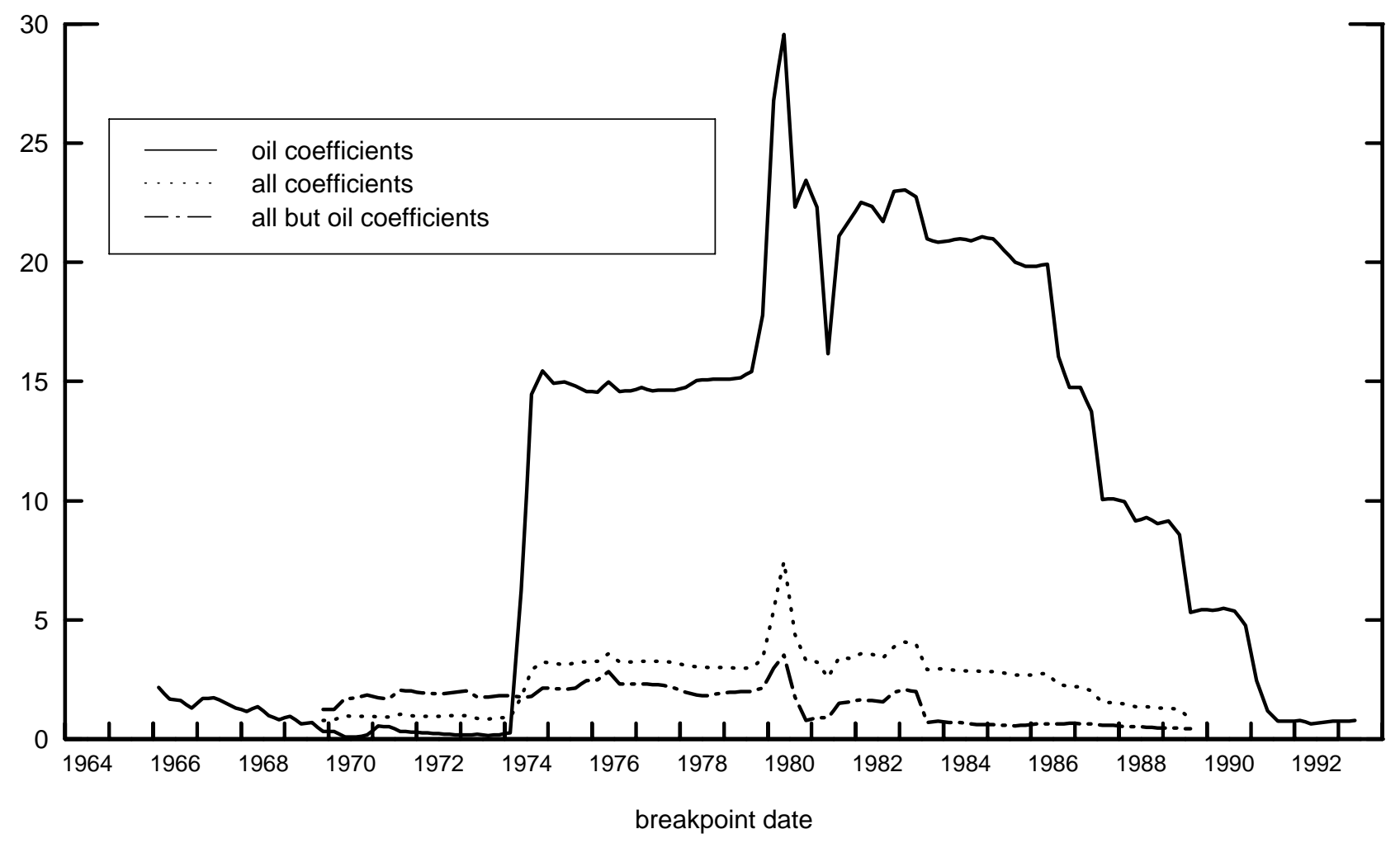


Fig 3a: Response of Funds Rate to Mork's Oil Price, 1954-80

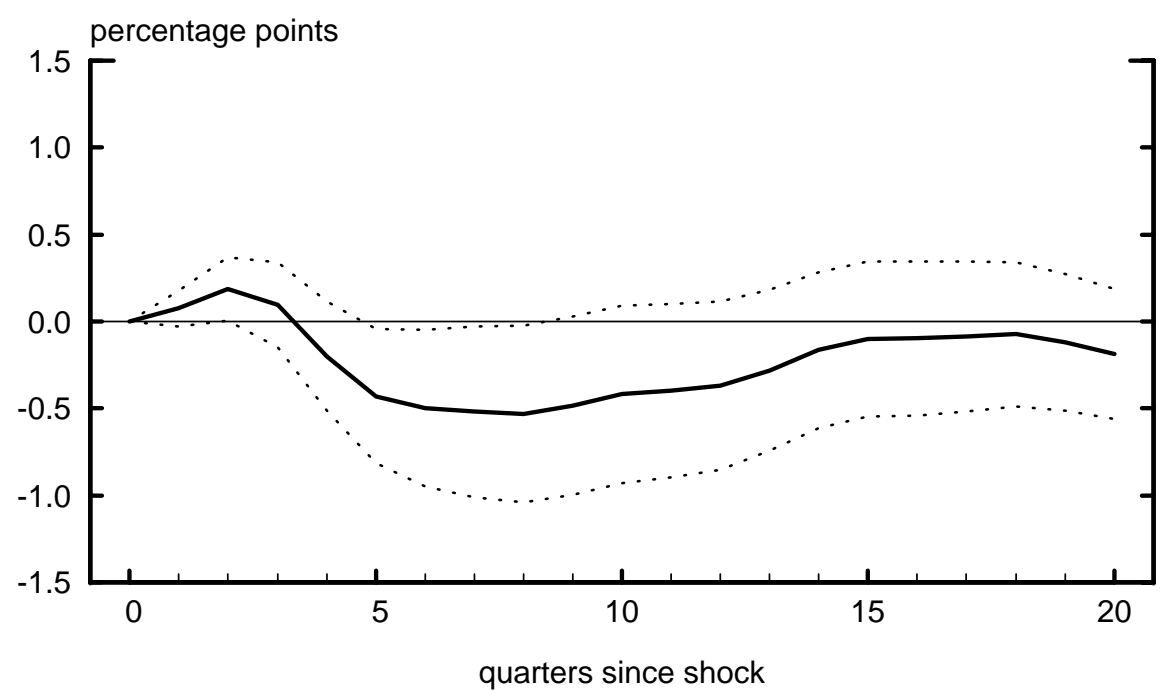

Fig 3c: Response of Funds Rate to Mork's Oil Price, 1980-98

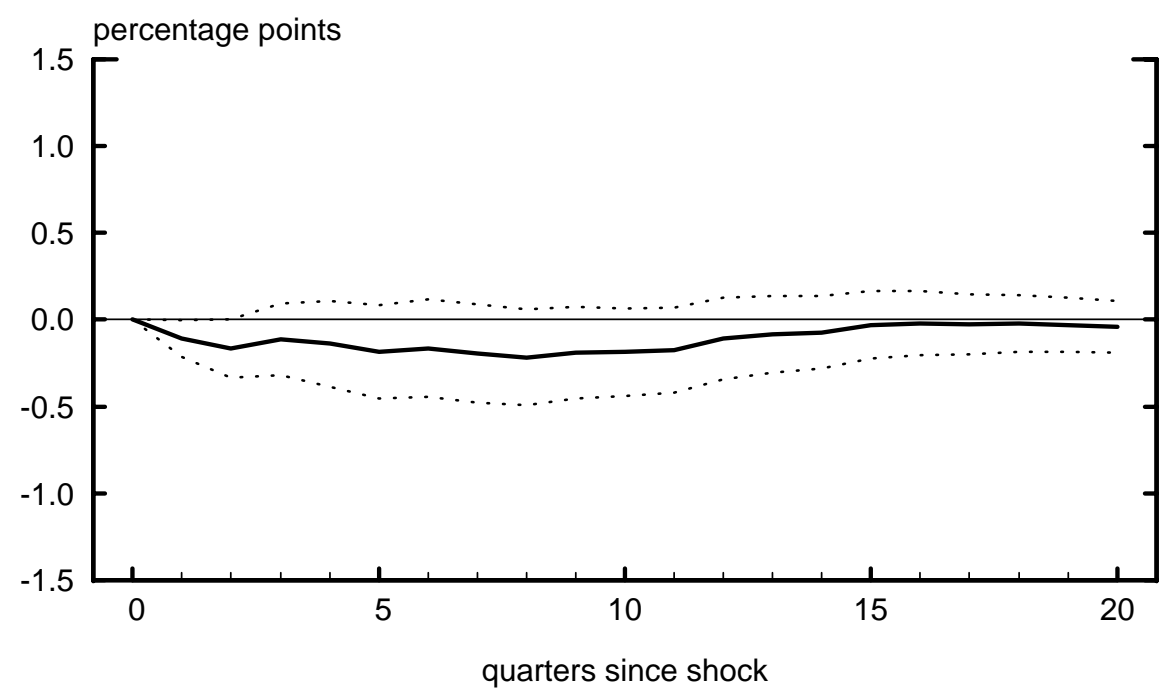

Fig 3b: Response of Funds Rate to NOPI Oil Price, 1954-80

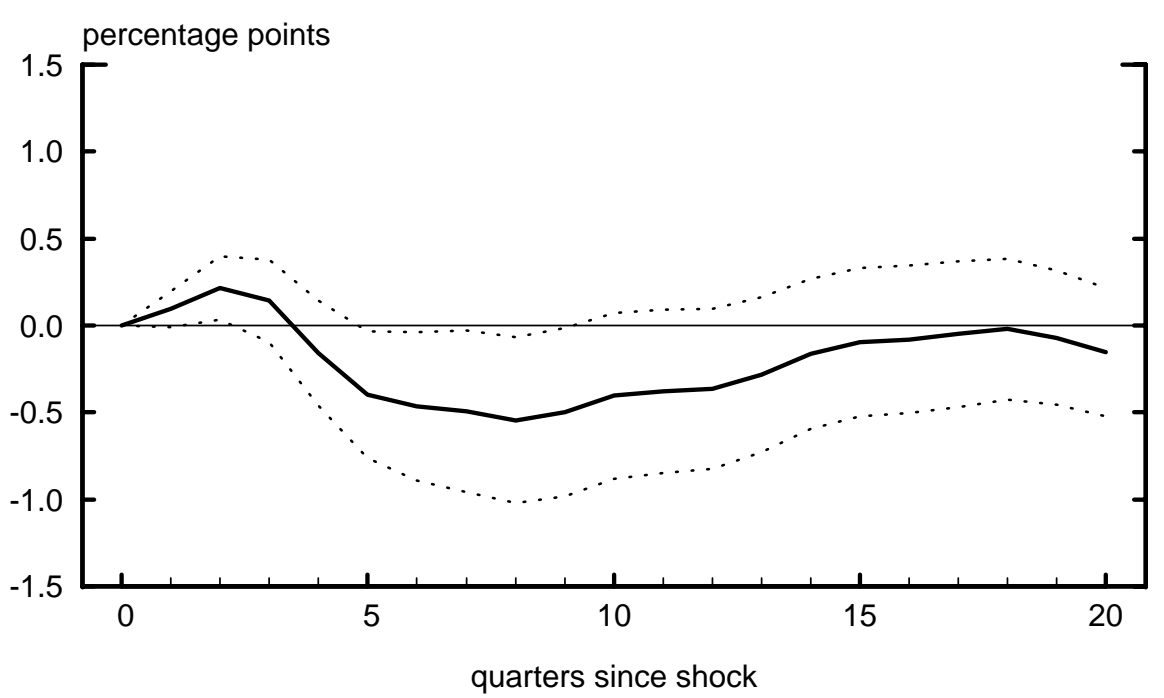

Fig 3d: Response of Funds Rate to NOPI Oil Price, 1980-98

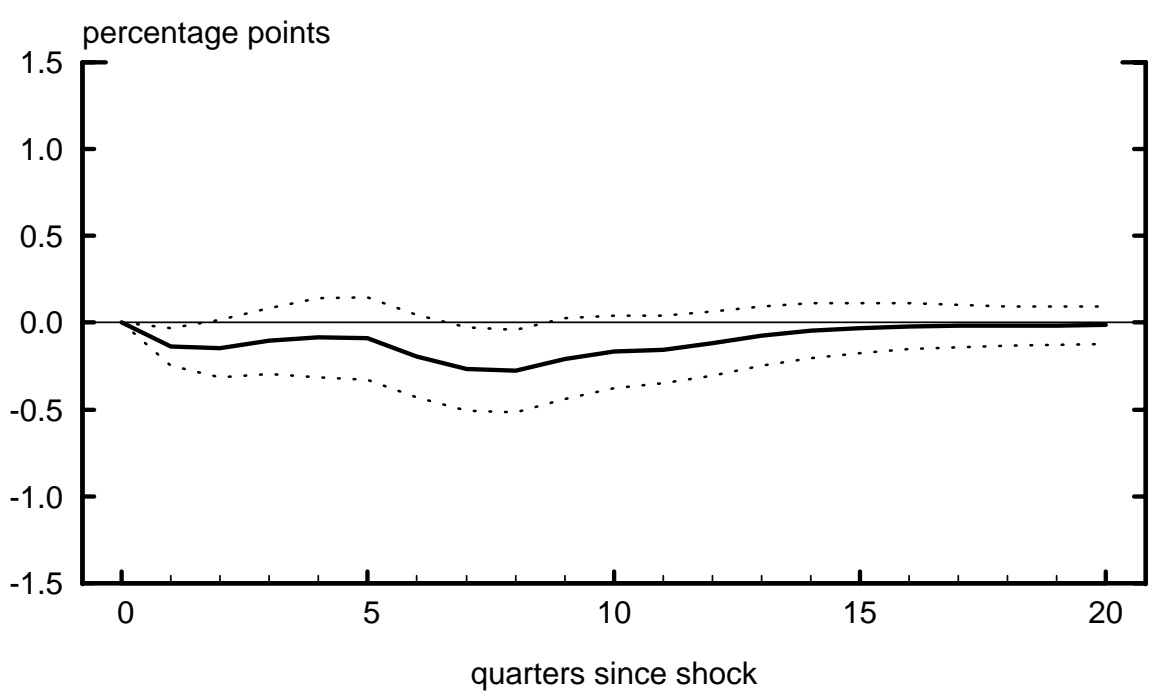

